\title{
Stefanelo Botarga: una máscara italiana para la España del siglo XVI
}

\author{
Ana Isabel Fernández Valbuena \\ RESAD (Real Escuela Superior de Arte Dramático), Madrid \\ dacapocb@yahoo.es
}

A lo largo de más de un decenio Valle Ojeda, autora de Stefanelo Botarga e Zan Ganassa. Scenari e zibaldoni di comici italianinella Spagna del Cinquecento (Bulzoni, Roma, 2007) ha ido desgranando los resultados de una investigación amorosa y precisa en torno a un cuaderno manuscrito del siglo XVI en publicaciones de menor envergadura que la que aquí se comenta, pero no de menor importancia. La suma de esta andadura constituye el citado estudio, editado en Italia y en italiano. Hay que felicitar por ello a la editorial Bulzoni, que atesora ya muchas otras obras de esta categoría, y lamentar que no haya, por ahora, editoriales españolas, ni siquiera institucionales, deseosas de hacer lo propio con este patrimonio español único, pues este cuaderno del tardo renacimiento es español por origen y destino.

Con la presente edición la investigadora se suma a otros notables predecesores en historiar el arte escénico hispano en sus usos, sus fuentes e influencias posteriores. Por ser no pocos, y todos vinculados directa o indirectamente al resultado de esta edición, no mencionaré más que a aquel que abrió camino directamente con su machete afilado en la selva hispana de los siglos XVI y XVII para llegar a este manuscrito: el eminente hispanista fallecido hace algunos años, Stefano Arata, al que está dedicado el volumen. Y es que el precioso manuscrito que aquí se desentraña y explica, perteneció a una compañía de actores de la primera generación de la Comedia del Arte, asentada en España. Se trata de una recopilación (zibaldone) única en su especie, por no haber sido pasada a limpio con la intención de legarla a los sucesores en la profesión, como lo fueron muchas de otras compañías, o incluso de editarla, como fue el caso de la antología italiana de Flaminio Scala (1611).

El manuscrito - hoy depositado en la Biblioteca del Palacio Real de Madrid y datado en torno a los años ochenta del 1.500 — formó parte de la Biblioteca del Conde de Gondomar, una de las más completas de su época, y presenta materiales dramáticos variopintos, e incluso no dramáticos, como las anotaciones de las cuentas de la compañía de Stefanelo Botarga, nombre de «arte» de Abagaro Frescobaldi, también conocido por el nombre genérico de la máscara que interpretaba, Magnifico, de la que Botarga es sólo una versión. 
Los tres nombres, Agabaro, Botarga y Magnifico se alternan indistintamente en el manuscrito, como sucedía con los de su camarada más conocido, Alberto Naselli, Ganassa «en arte», y también Zanni, encarnado en arquetipo de la commedia. Ganassa fue director de la primera compañía de cómicos del arte que se conoce en la península ibérica, a la que perteneció el autor de este manuscrito hasta su emancipación, que lo llevó a constituir su propia compañía, junto a la actriz vallisoletana Luisa de Aranda, quien fue su esposa.

Tuve la experiencia personal de enfrentarme a los originales de este cuaderno para la edición de una antología de canovacci que preparaba, y su desentrañamiento me resultó imposible. Sólo una labor paciente y sabia de cotejo grafológico, aplicación de destrezas paleográficas, lectura de lo ilegible, comparación de términos con posibles fuentes y tareas similares pueden llevar a interpretar primero y fijar después un texto repleto de abreviaturas y perteneciente a un género entonces no literario, sino de uso escénico, que sólo un par de décadas después comenzó a fijarse con la edición de antologías como la citada de Scala, tampoco traducida hasta hoy a nuestro idioma. En aquel momento de mi trabajo (2006) aún no había sido editado este precioso volumen de la doctora Ojeda, quien, no obstante, tuvo la generosidad de facilitarme la trascripción de uno de los canovacci de este manuscrito, para que fuera incluido en la antología traducida que yo preparaba. De modo que este manuscrito, finalmente impreso y con semejante aparato informativo, deviene un acontecimiento mucho más que filológico: un evento para la cultura teatral española que contribuye a ahondar en los vínculos profundos que unen a estas dos penínsulas del Mare Nostrum.

Dada la variedad textual que presenta el manuscrito la editora ha establecido, con acierto, una clasificación por géneros: canovacci, sentencias, tragedias, fragmentos escénicos, argucias, adivinanzas, glosas dramáticas, sonetos, iy hasta un auto sacramental fragmentado! Además de alguna nota de cuentas, como ya se ha dicho, que habla de la parte pragmática del oficio. Destacan entre estos materiales un par de prólogos casi preceptivos sobre el arte de la interpretación que, como afirma la autora, suponen un redescubrimiento del mismo. Cuántas conjeturas sobre este arte efímero podrán corroborar o rebatir los estudiosos a la luz de las aportaciones de Botarga, ahora exhumadas por Valle Ojeda. En efecto, el estilo imantador de las trazas de comedias (los canovacci) recogidos por Botarga como parte del repertorio de la compañía, en su brevedad, parece restar importancia a lo verbal y apelar a lo esencial, a lo más vivo del arte dramático: la representación. En eso se hermanan los canovacci con propuestas muy posteriores como las síntesis futuristas, piezas brevísimas no literarias, que describían las acciones a realizar. De hecho, fue la tradición de la Comedia del Arte una de las referencias míticas que circularon entre las primeras vanguardias del siglo XX. Y estos scenari, en su elemental sucesión de acciones dentro de la descarnada falta de decoro del teatro renacentista, cuántas veces nos recuerdan también a muchas farsas de los títeres de cachiporra, españolas, italianas, inglesas... Una forma teatral hermana de la Comedia del Arte, por la que sus arquetipos han circulado y circulan con pleno derecho. 
Como bien detalla la estudiosa, las fuentes para entender estos materiales y sus funciones se hallan en libros de miscelánea del siglo XVI (centones), especialmente del norte de Italia, o en dramaturgias contemporáneas a la actividad de Botarga, como la del tragediógrafo italiano Giraldi Cinzio, o la del español Diego Hurtado de Mendoza. Asimismo están presentes en estos materiales los autores clásicos, bien de primera mano (como parece ser el caso de Virgilio traducido directamente en sus Metamorfosis), bien referidos en las misceláneas, o a través de otros autores; son los casos de Horacio, Cicerón, Séneca... En estas transferencias a menudo se cambia el registro lingüístico, para adaptarlo desde las estructuras clásicas al espectáculo d'Arte. Porque los materiales recogidos, en su extraordinaria variedad, van desde los intermedios mitológicos, a fragmentos de obras pastoriles, trazas de comedias muy elementales en sus datos, pero perfectamente divididas en actos, incluso con sus entremeses intercalados, y, por supuesto, materiales de uso de los actores en la escena, las llamadas robe generiche. Estos últimos consisten en sonetos, prólogos y retahílas a insertar en los momentos oportunos, con independencia de la obra. Muy interesante a efectos de la comprensión y el mejor conocimiento de la interpretación de estos actores es la iniciativa de la editora de extraer un índice de las acciones codificadas mencionadas en los distintos canovacci, que suelen conocerse como lazzi. Su catalogación aparte se ofrece a un estudio comparativo que resultará muy fecundo para quien lo aborde, pues estas destrezas actorales presentan aún apasionantes preguntas por resolver.

La editora apunta, asimismo, que de una lectura atenta de todos estos materiales se desprenden conclusiones sobre la cosmovisión de esta época manierista, empapada de ideas estoicas (por ejemplo, en torno a la soledad) y senequistas, junto a otras visiones políticas cercanas a Maquiavelo, Guicciardini y Baltasar de Castiglione. Impresiona, de hecho, la impronta plenamente renacentista del manuscrito en la continua cita de fuentes clásicas (latinas), aunque a menudo éstas procedan de florestas y otras misceláneas recopilatorias. De entre esta diversidad merece destacarse algo de capital importancia para datar el nacimiento de la compañía de Botarga: el Prólogo numerado por la editora como el 172. Se trata de un prefacio canónico de captatio benevolentiae propio del teatro renacentista, aunque en este caso reviste carácter autobiográfico, pues su autor, en la máscara de Botarga, explica su separación de la compañía de Ganassa, con la que había llegado a Italia, y la asunción en la nueva compañía del estilo de interpretación «a la española», incluyendo también el uso de nuestra lengua. A pesar de su importancia para nosotros, su ubicación en el manuscrito se hallaba dispersa por varias páginas del cuaderno, separadas entre sí: las que habían quedado libres, pues su trascripción, tal como ha deducido Valle Ojeda, es fruto de una copia en limpio, y probablemente no quedaba ya espacio material para la misma en el cuaderno limitado. A estos hallazgos, reconstruidos como si se tratara de una excavación arqueológica, se suman los que son fruto de la reflexión y el cotejo, como los datos preciosos que se ofrecen sobre la mencionada compañía dirigida por Ganassa, de la que podemos extraer conclusiones como el gusto por los papeles en travestí (hombres que interpretan roles femeninos): Giaco- 
mo Portalupo, por ejemplo, hacía en los repartos de Ganassa el papel de la enamorada Isabella. Un uso común en otras geografías contemporáneas a esta, como la del teatro isabelino en Inglaterra, pero del que poseemos menos datos en lo tocante al teatro español, donde a lo largo de siglo XVI se conocen compañías teatrales compuestas tanto por actores como por actrices. Y lo mismo podemos decir de las compañías italianas, en las que hubo incluso directoras de agrupaciones teatrales que fueron mujeres desde mediados del siglo XVI. Todo ello no fue obstáculo para que muchos actores masculinos, desde el comienzo de la Comedia del Arte hasta su declive, interpretaran roles femeninos; el propio Carlo Gozzi, en las postrimerías del siglo XVIII, gustó de interpretar un papel de criada en sus años mozos, según él mismo afirmaba.

En realidad, todo este libro se ofrece a bucear en los datos, expresos o larvados, sobre las técnicas de puesta en escena, la preparación de los ensayos y la búsqueda de materiales escénicos, y textos de repertorio, italianos, españoles, latinos. Ése será uno de sus mayores logros: aportar a la historia de la interpretación actoral nuevos datos concretos que apoyen cuanto ya se sabe de este periodo, esclarecer puntos que se desconocían y, sobre todo, desmentir algunos lugares comunes que partían de hipótesis por confirmar —en el mejor de los casos- y de cuya presunta certeza han bebido no pocos manuales. En ellos varias generaciones - en España por lo menos - se han forjado creyendo, por ejemplo, que no se conservaban canovacci, o que los actores del Arte eran unos portentos de la improvisación que nunca ensayaban, y que no interpretaban obras de repertorio textual. Hallamos en esta joya documental, por ejemplo, canovacci de temas y fuentes españoles, como el titulado Ramiro, e intermedios, como el número 29, que son una verdadera ensalada de arquetipos cómicos (Zanni, Ganassa) junto a personajes propios de la comedia de magia (la maga, el monstruo Argano), y otros que pertenecen a las fábulas clásicas pastoriles, como Sireno y Floris. De hecho, esta trama itranscurre en la Arcadia! Usos muy cercanos a tantas obras representadas en los ambientes cortesanos de la España del siglo XVII, aquí embrionariamente tratados.

En lo estrictamente filológico del estudio, la autora afirma que su propuesta, digamos, hermenéutica, es una de entre las posibles, pues supone una lectura, ecdótica, sin duda, pero también una dirección concreta en la búsqueda, que parte de hipótesis construidas a lo largo de muchos años. De modo que su propuesta es la que por ahora le parece más plausible, sin que esté del todo cerrada. No obstante, el acabado del estudio es mucho más que suficiente y se abre a tal cantidad de rastreo, cotejo, invitaciones comparativas e incluso saqueo documental, que su plausibilidad deviene perfección. En su ejercicio de prudencia, afirma también Valle Ojeda que su Introducción no es sino una aproximación al texto; habida cuenta de que se trata de cien páginas y de que el aparato de notas en cada uno de los textos numerados para distinguirlos es mayor que el propio material creativo, la aproximación más parece una ampliación microscópica, lista para su lanzamiento nuclear. En dicha Introducción se documentan exhaustivamente las controversias sobre las primeras manifestaciones de actores italianos en España en fechas tempranas del siglo XVI. 
Con buen criterio, la autora ha hecho comenzar además la edición por una bibliografía (precedida de un breve prólogo de presentación), que refleja las distintas disciplinas que se han dado cita necesariamente para armar este rompecabezas planteado por un manuscrito de uso personal: la historia de la lengua, la historia del teatro, la lingüística, las fuentes literarias, los manuscritos históricos de scenari, los artículos especializados... Un conjunto no escaso, pero sin intención de apabullar, índice de la realidad que ha acompañado la preparación, desentrañamiento, fijación y estudio comparativo y de fuentes de estos textos. Se agradecen además las traducciones al italiano de los textos escritos originalmente en latín. Al tiempo, el índice onomástico facilita la consulta a los que se acerquen a este libro con objetivos más concretos que generales, dado que el manuscrito, recoge textos de distintos géneros fuentes y tradiciones dramáticas, por lo general procedentes además de tres lenguas (las tres lenguas que podía conocer Agabaro: el castellano, el italiano y el latín), por lo que el rastreo localización y redacción del aparato crítico ha resultado de gran complejidad. Asimismo la editora decidió incluir en apéndice otros canovacci de distintas colecciones, que guardan semejanzas con los reunidos en este zibaldone. Con ellos inserta este material español en la tradición de colecciones de scenari que se hallan en Italia, y que recogen materiales legados a lo largo de más de tres siglos.

Por ser la doctora Ojeda de origen español, la redacción primigenia de este libro se realizó en castellano, y para su edición italiana su primera versión se ha vertido en una traducción. Hay, de hecho, momentos en el libro en los que se percibe la vieja costura española en la nueva prenda de corte italiano. No se trata de un defecto, sólo de una observación que apenas apreciarán los lectores de lengua materna hispana avezados en la lectura crítica en italiano (pocos, a decir verdad). Cada día menos, tal vez.

Es cierto que las investigaciones en historia del teatro que llevan a cabo algunas instituciones y universidades españolas van dando a la comunidad científica cada vez datos más precisos sobre esta materia, y cabe citar, entre las últimas de cierta calidad y de la misma cronología que la obra aquí reseñada, el estudio de Alicia Álvarez Sellers (2008): Del texto a la iconografía. Aproximación al documento teatral del siglo XVII, Valencia, Universitat de València. Pero no es menos cierto que con alguna frecuencia las direcciones metodológicas más acertadas en este campo nos vienen fuera, o, como en este caso, se publican en otro idioma habiendo sido su autora "una de las nuestras». A pesar de que el teatro áureo español es uno de nuestros orgullos nacionales, sus raíces, usos y vínculos ofrecen aún espacios llenos de agujeros negros, que especialistas como Valle Ojeda van colmando con paciencia, sostenidas por el saber de cuantos la han precedido en tantas disciplinas como el volumen ha necesitado para ver la luz en las mejores condiciones. Con todos ellos cumple la especialista en el extenso elenco de agradecimientos.

Vaya el nuestro, y nuestra enhorabuena por un trabajo necesario y aquilatado, un verdadero cofre pleno de tesoros, del que, por fin, disfrutamos. En italiano, però. 